\title{
A new double w-shaped compact negative refractive index metamaterial for wideband applications
}

\author{
Pujan Chandra Paul ${ }^{1}$, Mohammad Jakir Hossain ${ }^{2}$, Ashish Kumar Karmaker ${ }^{3}$, Md. Jakirul Islam \\ ${ }^{1,2,3}$ Electrical and Electronic Engineering, Dhaka University of Engineering and Technology (DUET), Bangladesh \\ ${ }^{4}$ Computer Science and Engineering, Dhaka University of Engineering and Technology (DUET), Bangladesh
}

\begin{tabular}{l} 
Article Info \\
\hline Article history: \\
Received Feb 14, 2020 \\
Revised Apr 13, 2020 \\
Accepted Apr 27, 2020 \\
\hline
\end{tabular}

Keywords:

Multi-band

Negative refractive index metamaterial

Wideband

\section{Corresponding Author:}

Mohammad Jakir Hossain,

Department of Electrical and Electronic Engineering,

Dhaka University of Engineering and Technology (DUET),

Gazipur, Bangladesh.

Email: jakir@duet.ac.bd

\begin{abstract}
This paper analyzed the new compact design and negative refractive index (NRI) metamaterial for wideband applications. The proposed metamaterial exhibits NRI and wideband characteristics of the $\mathrm{x}$-axis wave propagation. It displayed the NRI property at the frequency of $1.54 \mathrm{GHz}$ and wideband from $1.26 \mathrm{GHz}$ to $7.08 \mathrm{GHz}$ frequency (L, S, and $\mathrm{C}$ band). Moreover, the response of the $1 \times 2$ horizontal and $2 \times 1$ vertical array structure showed the wideband frequency in the $7.17 \mathrm{GHz}$ to $13.62 \mathrm{GHz}$ and $1.46 \mathrm{GHz}$ to 9.53 $\mathrm{GHz}$, respectively. Electromagnetic simulation software called CST has been used to design the metamaterial unit cell. The metamaterial has been displayed the multi-band characteristics such as L, S, C, X and $\mathrm{K}_{\mathrm{u}}$ bands with negative index material properties.
\end{abstract}

Copyright $($ C 2020 Institute of Advanced Engineering and Science. All rights reserved.

\section{INTRODUCTION}

Metamaterial is an engineered material structure that has some unique electromagnetic properties that not found in the nature. Thus, metamaterials are artificially constructed that called left-handed metamaterials. They can exhibit the negative permittivity $(\varepsilon<0)$, negative permeability $(\mu<0)$ and the negative refractive index, Snell's law, etc. In 1968, Russian scientist Victor Veselago first time explained about this material property. It had some different properties compared with the conventional materials [1]. Almost 30 years later, in 2000 Smith et al. [2] practically demonstrated a composite material with negative metamaterial characteristics. These unique characteristic materials can be used in more important fields, namely sensor design, EM absorption, SAR reduction, filter design, antenna design, and invisibility cloaking operation. A metamaterial is called double-negative (DNG) material when the effective permittivity $(\varepsilon)$ and permeability $(\mu)$ are negative. If any of them of permittivity and permeability is negative, then the material called single negative (SNG) material. Some unit cell structure with metamaterial properties and double band electric atom with double split ring resonators are explained in literature [3-5]. There are some metamaterials structures have been proposed such as, Malik et al. with $25 \times 25 \mathrm{~mm}^{2}$ rectangular "U-shape" metamaterial that can display double negative properties for the various array structures [6].

Hossain et al. suggested a meta-atom, the dimention of the meta-atom was $12 \times 12 \times 1.6 \mathrm{~mm}^{3}$ with EMR (10.55) [7]. Zhou et al. designed a "double Z-Shape" metamaterial structure with double negative properties and the dimension of $8.5 \times 8.5 \mathrm{~mm}^{2}$ whereas the EMR was 4.80 [8]. Islam et al. suggested an "H shape" metamaterial structure with the size of $30 \times 30 \mathrm{~mm}^{2}$. This structure was shown the NRI properties at $0.5 \mathrm{GHz}$ and $0.3 \mathrm{GHz}$ frequency with small EMR (3.65) [9]. Rizwan et al. designed an "F-shape" metamaterial structure with NRI that were applicable of $K$ and $K_{u}$ bands [10]. Zhou et al. designed an 
"S-shape" chiral metamaterial. The dimension of the metamaterial was $15 \times 15 \mathrm{~mm}^{2}$ with $\mathrm{X}$ and $\mathrm{K}_{\mathrm{u}}$ band application [11]. Hossain et al. proposed a modified multiple hexagonal unit cell structure. The dimension of the structure was $11 \times 10 \times 1.6 \mathrm{~mm}^{3}$ and the EMR was 13.84 [12]. Hossain et al. designed a "G-Shape" a new wideband double negative metamaterial and the dimension was $12 \times 12 \times 1.6 \mathrm{~mm}^{3}$ whereas the EMR was 11.90 [13]. Hasan et al. proposed a "Modified Z-shape" double-negative miniaturized metamaterial for wideband operation. The dimension of the structure was $10 \times 10 \times 1.6 \mathrm{~mm}^{3}$ and the EMR was 3.98 [14]. Abhishek et al. designed dual band metamaterial unit-cell structure with dimension was $7.5 \times 7.5 \times 0.787$ $\mathrm{mm}^{3}$ and the EMR was 7.14 [15]. Hossian et al. proposed a "double C-shape" metamaterial structure dimension of $12 \times 12 \times 1.6 \mathrm{~mm}^{3}$ and the EMR was 9.62 [16]. Abbott et al. designed a compact capacitive loading design to improve the effective medium ratio [17]. In 2010 Fabio Urbani et al. proposed a "diamond-shaped" metamaterial unit-cell for X-band only and the EMR was too small 1.2 [18]. Karamanos et al. designed a compact double negative metamaterial unit cell with EMR 6.9 [19]. Nabila Abdul Jaffar et al. designed a metamaterial-base antenna for non-invasive hyperthermia cancer treatment [20]. Bashar et al. proposed a dual band modified split square resonator metamateraial structure [21]. Adamu et al. designed a metamaterial antenna employing SSR and CSRR for WLAN application [22]. Hossain et al. designed a "combination of double T- and double U-shaped split ring resonators with square split ring resonator" metamaterial in the microwave range, whereas the size of the published design structure was $10.5 \times 12 \times 1.6 \mathrm{~mm}^{3}$ that was large compared to proposed design structure [23].

In this paper, the design of "double Ш- shaped" with a split square resonator metamaterial unit cell structure exhibits the multi-band characteristics of L, S, C, X and $\mathrm{K}_{\mathrm{u}}$ bands with wideband frequency of 1.26 $\mathrm{GHz}$ to $7.08 \mathrm{GHz}(5.62 \mathrm{GHz}), 7.17 \mathrm{GHz}$ to $13.62 \mathrm{GHz}(6.45 \mathrm{GHz}), 1.46 \mathrm{GHz}$ to $9.53 \mathrm{GHz}(8.07 \mathrm{GHz})$ for the $\mathrm{X}$-axis wave propagation. The different types of array structure such as $1 \times 2$ horizontal, and $2 \times 1$ vertical were described in this paper. The proposed compact design of metamaterial unit cell also displayed the negative refractive index properties at $1.53 \mathrm{GHz}, 1.68 \mathrm{GHz}, 6.16 \mathrm{GHz}, 6.045 \mathrm{GHz}$ resonance frequencies. In this paper, the size of the suggested unit cell structure is $9.6 \times 9.6 \times 1.6 \mathrm{~mm}^{3}$, which is more compact than the reference metamaterial structure with the terms of EMR (20.29). Electromagnetic simulation software called CST has been used to design the metamaterial unit cell structure for multi-band application.

\section{DESIGN AND METHODOLOGY}

The NRI metamaterial unit cell is a two-layer copper substance with "double Ш-shape" and split square resonator printed on the FR4 lossy material substrate. The dimension of the substrate is $9.6 \times 9.6 \times 1.6$ $\mathrm{mm}^{3}$ and thickness of $0.035 \mathrm{~mm}$ with permittivity, $\varepsilon=4.3$, permeability, $\mu=1$, and loss tangent, $\delta=0.025$. The metamaterial unit cell's parameters are $\mathrm{L}=9 \mathrm{~mm}, \mathrm{~W}=9 \mathrm{~mm}, \mathrm{~W}_{1}=0.5 \mathrm{~mm}, \mathrm{~W}_{2}=0.5 \mathrm{~mm}, \mathrm{~W}_{3}=0.5 \mathrm{~mm}$, $\mathrm{L}_{1}=5.8 \mathrm{~mm}, \mathrm{~L}_{2}=7 \mathrm{~mm} \mathrm{~g}=0.4 \mathrm{~mm}, \mathrm{~g}_{2}=0.4 \mathrm{~mm}, \mathrm{~g}_{3}=0.6 \mathrm{~mm}, \mathrm{~g}_{4}=0.5 \mathrm{~mm}$.

In this paper, electromagnetic simulation software called CST has been utilized to obtain the NRI and wideband properties of the metamaterial unit cell structure. The structure is placed in between the positive and negative waveguide ports along the $\mathrm{X}$-axis wave propagation to execute the NRI and the wideband operation where $\mathrm{Y}$-axis and Z-axis represent perfect electric conductor (PEC) and perfect magnetic conductor (PMC) respectively for boundaries. To simulate S-parameters, a frequency domain solver is used where 1001 sample frequencies have been taken. The simulation was performed between the frequency ranges of $1 \mathrm{GHz}$ to $15 \mathrm{GHz}$. The proposed metamaterial unit cell's formation diagram is shown in Figure 1.

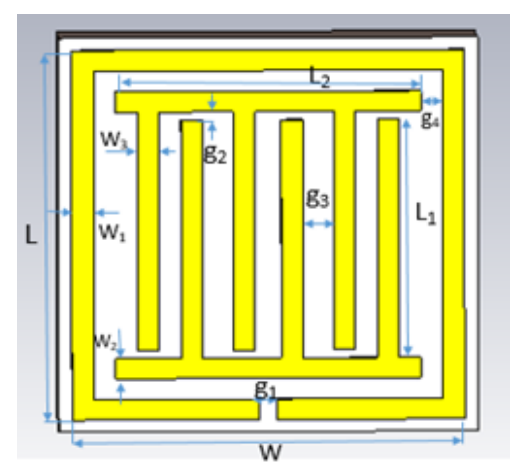

(a)

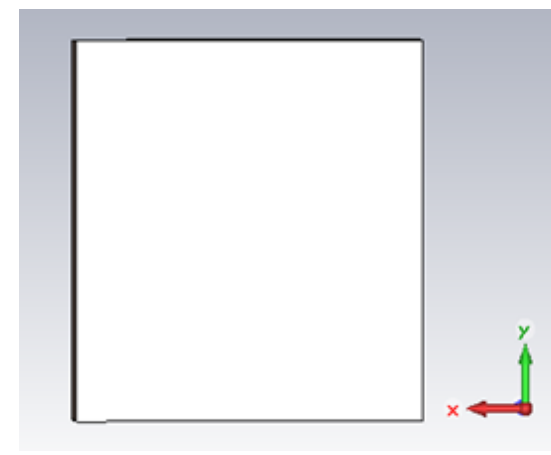

(b)

Figure 1. The sketch diagram of the proposed unit cell structure, (a) Front side, (b) Back side 


\section{RESULTS AND DISCUSSION}

Generally, Direct-Retrieval method [24], Direct Refractive Index method and the Nicolson-Rose-Weir (NRW) method are used to extract the effective parameters [25]. In this case, both (real and imaginary) values of permittivity $(\varepsilon)$, permeability $(\mu)$ and refractive index $(n)$ are determined from the simulated complex S-parameters such as reflection coefficient $\left(S_{11}\right)$ and transmission coefficient $\left(S_{21}\right)$. This paper analyzes the $X$-axis wave propagation and the different types of array structure such as $1 \times 2$ horizontal and $2 \times 1$ vertical array respectively.

\subsection{Analysis of EM wave propagation for the $\mathrm{X}$-axis}

The metamaterial unit cell structure is between the positive and negative waveguide ports along the $\mathrm{X}$-axis wave propagation where $\mathrm{Y}$-axis and Z-axis represent perfect electric conductor (PEC) and perfect magnetic conductor (PMC) respectively for boundaries. Figure 2(a) showed the simulated configuration and 2(b) showed the magnitude of $\mathrm{S}$-parameters with $\mathrm{X}$-axis wave propagation. The reflection coefficient $\left(\mathrm{S}_{11}\right)$ displays the maximum resonance at the $1.3 \mathrm{GHz}$ and $7.13 \mathrm{GHz}$ frequencies. Since the transmission coefficient $\left(\mathrm{S}_{21}\right)$, the maximum resonances at 1.54 $\mathrm{GHz}, 8.46 \mathrm{GHz}, 12.33 \mathrm{GHz}$ frequencies. Whereas the structure depicts the operation bands are $\mathrm{L}, \mathrm{S}, \mathrm{C}$ and $\mathrm{X}$ bands. Figure 3(a) and (b) display the effective permittivity and effective permeability with real and imaginary curves for Xaxis wave propagation. Figure 3(a) shows the real value of negative permittivity from $1.38 \mathrm{GHz}$ to $6.99 \mathrm{GHz}$, and $12.95 \mathrm{GHz}$ to $14.98 \mathrm{GHz}$. The real value of negative permeability from $1.34 \mathrm{GHz}$ to $1.46 \mathrm{GHz}, 6.29 \mathrm{GHz}$ to 7.13 $\mathrm{GHz}$ and $7.67 \mathrm{GHz}$ to $13.94 \mathrm{GHz}$ are shown in the Figure 3(b). Figure 3(c) exhibits the negative refractive index with both curves (real and imaginary) for the $\mathrm{X}$-axis wave propagation. The real values of negative refractive index are indicated from $1.37 \mathrm{GHz}$ to $6.99 \mathrm{GHz}$ and $12.56 \mathrm{GHz}$ to $14.04 \mathrm{GHz}$. The metamaterial unit cell exhibits the NRI property at $1.53 \mathrm{GHz}$ and the wideband at the frequencies of $1.26 \mathrm{GHz}$ to $7.08 \mathrm{GHz}$ (5.62 GHz bandwidth).

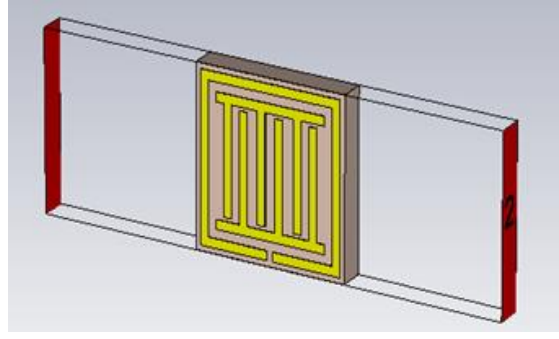

(a)

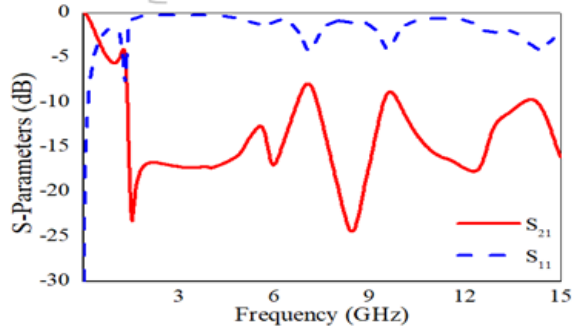

(b)

Figure 2. (a) Simulation setup, (b) Numerical S-parameters

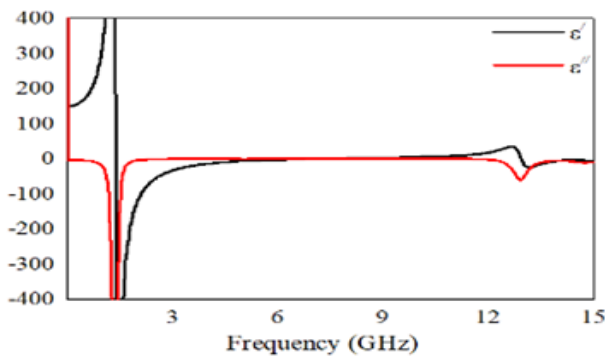

(a)

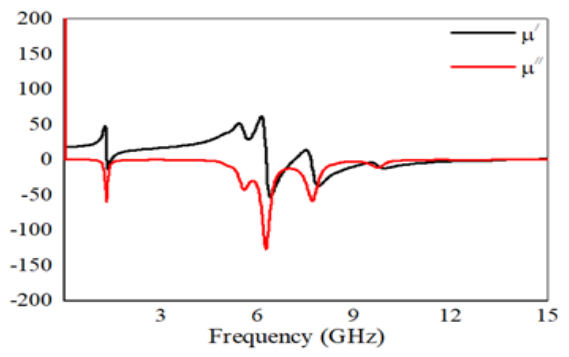

(b)

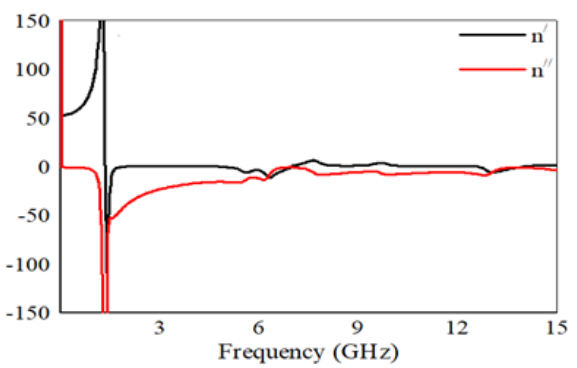

(c)

Figure 3. Real and imaginary curve of (a) Effective permittivity, (b) Effective permeability, (c) Effective refractive index for the $\mathrm{X}$-axis wave propagation 


\subsection{Analysis of $1 \times 2$ horizontal array of the metamaterial unit cell structure}

Figure 4(a) shows simulation setup for $1 \times 2$ horizontal array which is formed in the same substrate as basic unit cell structure and Figure 4(b) displays the numerical S-parameters in $1 \times 2$ horizontal array structure. The reflection coefficient $\left(\mathrm{S}_{11}\right)$ displays the maximum resonance frequencies at $1.13 \mathrm{GHz}$ and $9.42 \mathrm{GHz}$. The maximum peak of the resonance frequencies are $1.53 \mathrm{GHz}, 6.07 \mathrm{GHz}$, and $10.86 \mathrm{GHz}$ in the transmission coefficient $\left(\mathrm{S}_{21}\right)$. The applicable bands are L, S, C, X and $\mathrm{K}_{\mathrm{u}}$ bands. Figure 5(a) and 5(b) represents the effective permittivity and effective permeability with real and imaginary curves for $1 \times 2$ horizontal array structure. In the Figure 5(a), the real values of negative permittivity from $0.84 \mathrm{GHz}$ to 6.51 GHz, 7.17 GHz to $7.35 \mathrm{GHz}$ and $13.41 \mathrm{GHz}$ to $15 \mathrm{GHz}$ are illustrated. Figure 5(b) shows the real value of the negative permeability of $1.07 \mathrm{GHz}$ to $1.32 \mathrm{GHz}, 6.95 \mathrm{GHz}$ to $14.1 \mathrm{GHz}$ and Figure 5(c) exhibits the negative refractive index with the real and imaginary curves for the $1 \times 2$ horizontal array. The real values of the relative negative refractive index of $0.96 \mathrm{GHz}$ to $1.3 \mathrm{GHz}, 1.53 \mathrm{GHz}$ to $5.01 \mathrm{GHz}, 5.91 \mathrm{GHz}$ to $6.29 \mathrm{GHz}, 6.98 \mathrm{GHz}$ to $8.27 \mathrm{GHz}, 9.36 \mathrm{GHz}$ to $9.62 \mathrm{GHz}, 10.59 \mathrm{GHz}$ to $11.37 \mathrm{GHz}$ and $13.26 \mathrm{GHz}$ to 14.27 GHz. The structure of the $1 \times 2$ horizontal array exhibits the NRI resonant at $6.05 \mathrm{GHz}$ and the wideband of $7.17 \mathrm{GHz}$ to $13.62 \mathrm{GHz}(6.45 \mathrm{GHz}$ bandwidth).

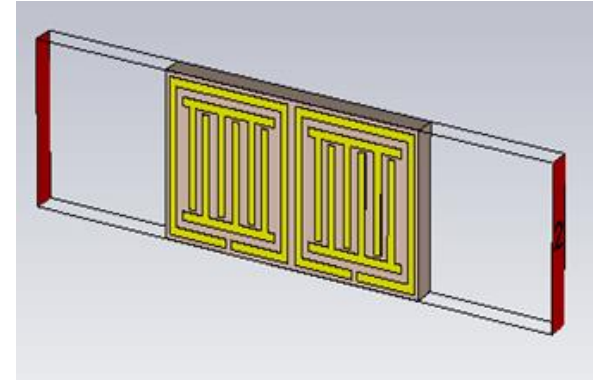

(a)

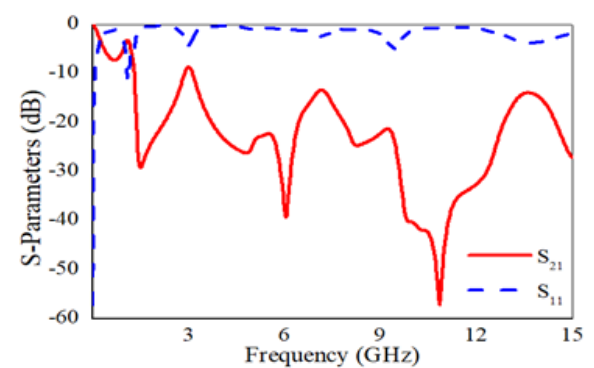

(b)

Figure 4. (a) Simulation setup for $1 \times 2$ horizontal array,

(b) Numerical $\mathrm{S}$-parameters in $1 \times 2$ horizontal array structure

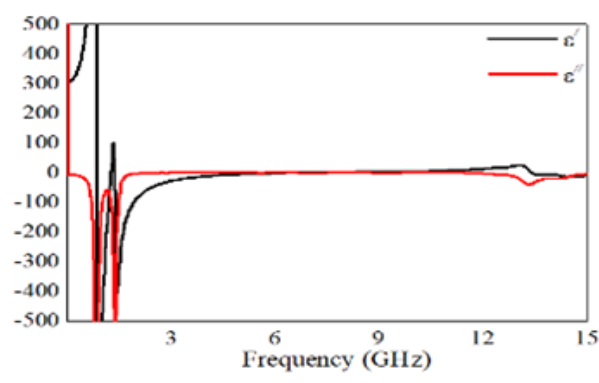

(a)

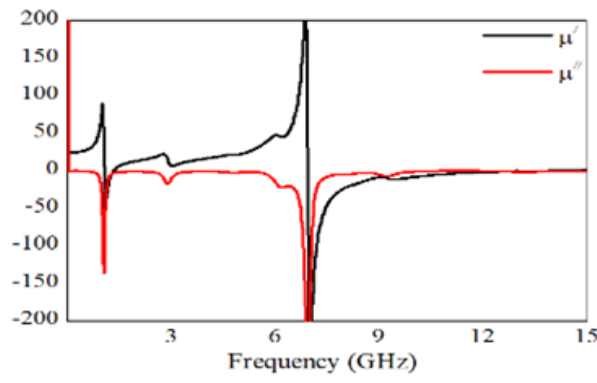

(b)

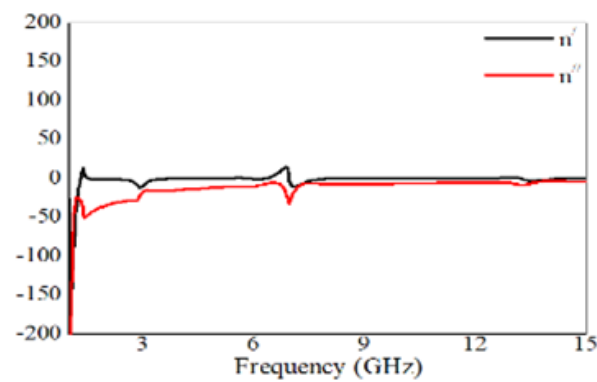

(c)

Figure 5. Real and imaginary curve of (a) Effective permittivity, (b) Effective permeability, (c) Effective refractive index for the $1 \times 2$ horizontal array 


\subsection{Analysis of $2 \times 1$ vertical array of the metamaterial unit cell structure}

Figure 6(a) indicates the simulation arrangement for $2 \times 1$ vertical array which is formed in the same substrate. Figure 6(b) shows the numerical S-parameters in the $2 \times 1$ vertical array structure. The reflection coefficient $\left(S_{11}\right)$ displays the maximum deep of the resonance at $1.33 \mathrm{GHz}$ and $9.49 \mathrm{GHz}$. The maximum deep of the resonance frequencies at $1.69 \mathrm{GHz}, 7.56 \mathrm{GHz}$, and $12.09 \mathrm{GHz}$ in the transmission coefficient $\left(S_{21}\right)$. However, the represented bands are L, S, C, X and $K_{u}$ bands. Figure 7(a) and 7(b) demonstrates the effective permittivity and effective permeability with real and imaginary curves. The real values of negative permittivity from $1.37 \mathrm{GHz}$ to $6.98 \mathrm{GHz}, 12.96 \mathrm{GHz}$ to $15 \mathrm{GHz}$ are shown in Figure 7(a). Figure 7(b) exhibits the real values of the negative permeability of $1.49 \mathrm{GHz}$ to $1.58 \mathrm{GHz}, 6.45 \mathrm{GHz}$ to $6.95 \mathrm{GHz}$ and $7.26 \mathrm{GHz}$ to $13.95 \mathrm{GHz}$. Figure 7(c) represents the negative refractive index with both curves (real and imaginary) for the $2 \times 1$ vertical array. The real values of the relative negative refractive index of $1.39 \mathrm{GHz}$ to $2.88 \mathrm{GHz}, 3.05 \mathrm{GHz}$ to $6.99 \mathrm{GHz}, 12.47 \mathrm{GHz}$ to $14.01 \mathrm{GHz}$. The structure of the $2 \times 1$ vertical array exhibits the NRI property at $1.68 \mathrm{GHz}$ and the wideband of $1.46 \mathrm{GHz}$ to $9.53 \mathrm{GHz}(8.07 \mathrm{GHz}$ bandwidth). Comparison among previous configurations and proposed configurations as shown in Table 1.

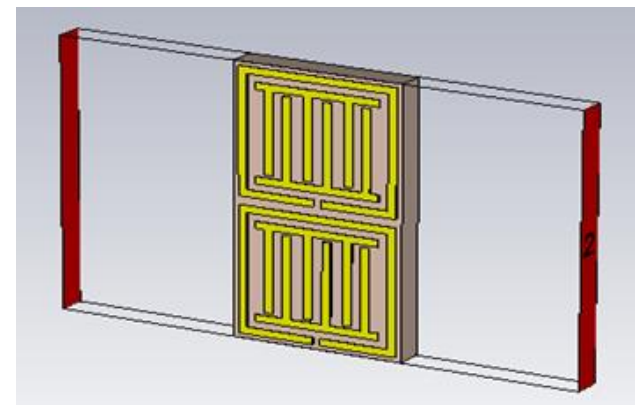

(a)

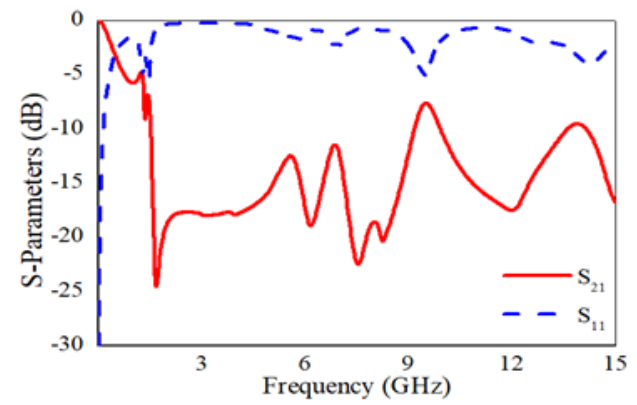

(b)

Figure 6. (a) Simulation setup, (b) Numerical S-parameters curve of $2 \times 1$ horizontal array structure

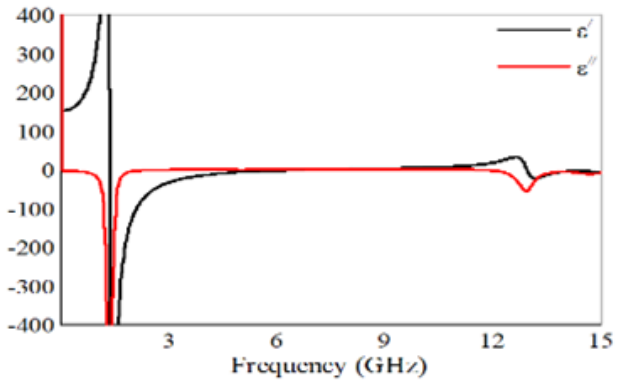

(a)

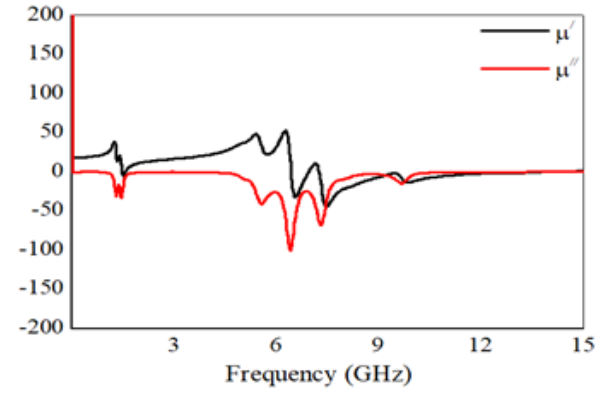

(b)

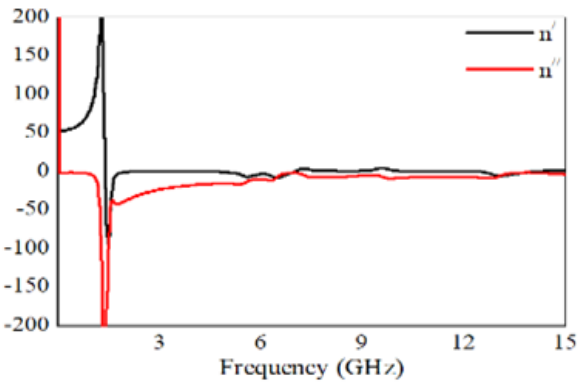

(c)

Figure 7. Real and imaginary curve of (a) Effective permittivity, (b) Effective permeability, (c) Effective refractive index for the $2 \times 1$ vertical array 
Table 1. Comparison among previous configurations and proposed configurations

\begin{tabular}{cccccc}
\hline Author's name & $\begin{array}{c}\text { Dimension } \\
\left(\mathrm{mm}^{3}\right)\end{array}$ & $\begin{array}{c}\text { Applicable } \\
\text { band }\end{array}$ & Unit-cell shape & $\begin{array}{c}\text { Metamaterial } \\
\text { type }\end{array}$ & EMR \\
\hline Islam et al. [9] & $30 \times 30 \times 1.6$ & $(2-15) \mathrm{GHz}$ & H -shape & LHM & 3.65 \\
Hossain et al. [13] & $12 \times 12 \times 1.6$ & $(0.5-6) \mathrm{GHz}$ & G-shape & NIM & 11.90 \\
Zhou et al. [8] & $8.5 \times 8.5$ & $(6-12) \mathrm{GHz}$ & Double Z shape & LHM & 4.80 \\
Hasan et al. [14] & $10 \times 10 \times 1.6$ & $(2-14) \mathrm{GHz}$ & Modified Z & SNM & 3.98 \\
Hossain et al. [7] & $12 \times 12 \times 1.6$ & $(1-15) \mathrm{GHz}$ & Double C & NIM & 10.55 \\
Hossain et al. [12] & $11 \times 10 \times 1.6$ & $(1-18) \mathrm{GHz}$ & Modified Hexagonal & LHM & 13.84 \\
Proposed unit cell & $9.6 \times 9.6 \times 1.6$ & $(1-15) \mathrm{GHz}$ & Double W & NIM & 2015 \\
\hline
\end{tabular}

\section{CONCLUSION}

The proposed double Ш-Shaped compact metamaterial unit cell structure designed on FR4 substrate material for NRI and wideband operation. It showed the NRI property at $1.54 \mathrm{GHz}$ resonance frequency and $5.62 \mathrm{GHz}$ bandwidth for $\mathrm{X}$ - axis wave propagation. Moreover, the analysis on $1 \times 2$ horizontal and $2 \times 1$ vertical array structure respectively exhibited the wideband of $6.45 \mathrm{GHz}(7.17 \mathrm{GHz}$ to $13.62 \mathrm{GHz})$ and $8.07 \mathrm{GHz}(1.46 \mathrm{GHz}$ to $9.53 \mathrm{GHz})$ that indicated $\mathrm{L}, \mathrm{S}, \mathrm{C}, \mathrm{X}$, and $\mathrm{K}_{\mathrm{u}}$ bands. This metamaterial unit cell structure displayed the higher EMR (20.29) compare to the mentioned metamaterial unit cell design structure. Electromagnetic simulation software called CST was been utilized to analysis the metamaterial unit cell structure. The proposed metamaterial is applicable for satellite communications, GPS, radar, long distance radio telecommunications, military telemetry, mobile phones (GSM).

\section{REFERENCES}

[1] V. G. Veselago, "The electrodynamics of substances with simultaneously negative values of $\varepsilon$ and $\mu$," Soviet Physics Uspekhi, vol. 10, no. 4, pp. 509-514, 1968.

[2] D. R. Smith, et al., "Composite medium with simultaneously negative permeability and permittivity," Physical Review Letters, vol. 84, p. 4184, 2000.

[3] A. Sarkhel, et al., "A compact metamaterial with multi-band negative-index characteristics," Applied Physics A, vol. 122, pp. 1-10, 2016.

[4] B. Zarghooni and T. A. Denidni, "New compact metamaterial unit-cell using SIR technique," IEEE Microwave and Wairless Components Letters, vol. 24, no. 5, pp. 315-317, 2014.

[5] J. D. Baena, et al., "Equivalent-circuit models for split-ring resonators and complementary split-ring resonatorscoupled to planar transmission line," IEEE transections on Microwave Theory Techniques, vol. 53, no. 4, pp. 1451-1461, 2005.

[6] A. Malik, et al., "Design of a novel two rectangular U-shaped double negative metamaterial," in International conference on Informatics, Electronics and Vision (ICIEV), Dhaka, Bangladesh, pp. 1-6, 2013.

[7] M. J. Hossain, et al., "An effective medium ratio obeying meta-atom for multiband applications," Bulletin of the polish academy of sciences technical science, vol. 65, no. 2, pp. 139-147, 2017.

[8] H. Zhou, et al., "A novel double-incidence and multi- band left-handed metamaterials composed of double Zshaped structure," Journal of Materials Science: Materials in Electronics, vol. 27, pp. 2534-2544, 2016.

[9] S. S. Islam, et al., "The design and analysis of a novel split-H-shaped metamaterial for multi-band microwave application," Materials, vol. 7, pp. 4994-5011, 2014.

[10] M. Rizwan, et al., "Dual-band tunable negative refractive index metamaterial with F-Shape structure," Central European Journal of Physics, vol. 12, pp. 578-581, 2014.

[11] Z. Zhou and H. Yang, "Triple-band asymmetric transmission of linear polarization with deformed S-shape bilayer chiral metamaterial," Appled Physics A, vol. 119, pp. 115-119, 2015.

[12] M. J. Hossain, et al., "Effective medium ratio obeying wideband left-handed miniaturized meta-atoms for multiband applications," Journal of Electronic Materials, vol. 47, pp. 1859-1870, 2018.

[13] M. I. Hossain, et al., "A New Wide-Band Double-Negative Metamaterial for C- and S-Band Appli- cations," Materials, vol. 8, pp. 57-71, 2015.

[14] M. M. Hasan, et al., "A new compact double-negative miniaturized metamaterial for wideband operation," Materials, vol. 9, no. 10, p. 830, 2016.

[15] A. Sarkhel, et al., "A compact meta-atom for dual band negative permittivity metamaterial," Microwave and Optical Technology Letters, vol. 57, no. 5, pp. 1152-1156, 2015.

[16] M. J. Hossain, et al., "A new miniaturized negative-index meta-atom for tri-band application," Open physics, vol. 15, no. 1, pp. 464-471, 2017.

[17] W. Withayachumnankul, et al., "Compact electric-LC resonators for metamaterials," Optics Express, vol. 18, no. 25 , pp. 25912-25921, 2010.

[18] F. Urbani, "Experimental analysis of novel single-sided lefthanded metamaterial," IEEE Antennas and Wireless Propagation Letters, vol. 9, pp. 720-723, 2010.

[19] T. D. Karamanos, et al., "Compact double-negative metamaterials based on electric and magnetic resonators," IEEE Antennas and Wireless Propagation Letters, vol. 11, pp. 480-483, 2012. 
[20] N. A. Jaffar, et al., "An overview of available metamaterial-based antenna for non-invasive hyperthermia cancer treatment," Indonesian Journal of Electrical Engineering and Computer Science, vol. 14, no. 2, pp. 697-705, 2019.

[21] B. A. F. Esmail, et al., "Dual band low loss metamaterial structure at millimetre wave band," Indonesian Journal of Electrical Engineering and Computer Science, vol. 15, no. 2, pp. 823-830, 2019.

[22] A. Y. Iliyasu, et al., "Wideband frequency reconfigurable metamaterial antenna employing SSR and CSRR for WLAN application," Indonesian Journal of Electrical Engineering and Computer Science, vol. 15, no. 3, pp. 1436-1442, 2019.

[23] M. J. Hossain, et al., "A new double T-U-shaped biaxial compact double-negative meta-atom for multiband applications," Microwave and Optical Technology Letters, vol. 59, no. 10, pp. 2551-2557, 2017.

[24] S. S. Islam, et al., "A new direct retrieval method of refractive index for the metamaterial," Current Science, vol. 109, no. 2, pp. 337-342, 2015.

[25] A. M. Nicolson and G. F. Ross, "Measurement of the intrinsic properties of materials by time-domain techniques," IEEE Transections on Instrumentation and Measurement, vol. 19, no. 4, pp. 377-382, 1970.

\section{BIOGRAPHIES OF AUTHORS}
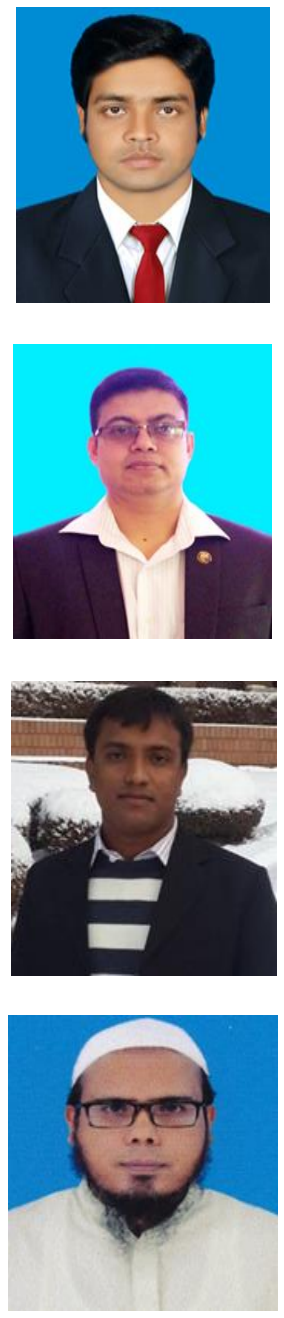

Pujan Chandra Paul received his B. Sc Engineering Degree in Electrical and Electronic Engineering from Daffodil International University, Bangladesh. He is now working as an Instructor in Electro-Medical Technology in Brahmanbaria Polytechnic Institute, Bangladesh.

Mohammad Jakir Hossain received a Ph. D. degree in Space Science from the Universiti Kebangsaan Malaysia (UKM) in 2019. He has authored or co-authored approximately 24 referred journals, 4 book chapters and 8 conference papers. He is currently an associate professor of electrical and electronic engineering department at Dhaka University of Engineering and Technology (DUET), Gazipur, Bangladesh. His research interests include the antenna, electromagnetic field and propagation, electromagnetic radiation absorption, metamaterials and metamaterial-based absorbers applications, and energy harvesting. Mr. Hossain is now a life fellow of the Institution of Engineers, Bangladesh (IEB).

Ashish Kumar Karmaker is currently working as an assistant professor, Department of Electrical and Electronic Engineering, Dhaka University of Engineering \& Technology, Gazipur, Bangladesh. He achieved M. Sc and B. Sc in Electrical and Electronic Engineering from Dhaka University of Engineering \& Technology, Gazipur in 2019 and 2012 respectively. In addition, he obtained Postgraduate Diploma in Information and Communication Technology from National Academy for Planning and Development, Dhaka in 2015. His research interests are power system, Renewable Energy, and different topics of Electrical and Electronic Engineering.

Dr. Md. Jakirul Islam was born in Nilphamari, Bangladesh, in 1980. He received the B.Sc. and M.Sc. degrees from Dhaka University of Engineering \& Technology, Gazipur, Bangladesh and University of Malaya, Malaysia, respectively. He received the Ph.D. degree in Computer Science and Engineering at RMIT University, Melbourne, Australia in 2018. He joined the Department of Computer Science and Engineering, Dhaka University of Engineering \& Technology in 2017 as a lecturer. Currently he is working as an Assistant Professor in the same university. He has been teaching several courses for under-graduated and graduated students. He has also supervising several M.Sc. and undergraduate thesis. His current research interests include discrete optimization. He has published more than 14 scientific papers. 